\title{
Proposal of a magnetically levitated shaded pole induction motor
}

\author{
Nobuyuki KURITA *, Takeo ISHIKAWA * and Genri SUZUKI * \\ *Division of Electronics and Informatics, Faculty of Science and Technology, Gunma University \\ 1-5-1 Tenjin-cho, Kiryu, Maebashi, 376-8515, Japan \\ E-mail:nkurita@gunma-u.ac.jp
}

Received 19 December 2014

\begin{abstract}
A magnetic bearing supports a rotary shaft without any contact by magnetic force, but such a system is complex due to additional mechanical and electrical components. In order to reduce the size and complexity of the driving circuit of the bearingless motor, this paper proposes a magnetically levitated shaded pole induction motor. The rotor is still supported by magnetic force, but the motor has a very simple structure because magnetic levitation and rotation can be achieved with only one amplifier. The operating principle of the shaded pole motor was confirmed by FEM magnetic field analysis. The suspension force and rotational torque have also been analyzed. It was found that in order to support and rotate a rotor, large amount of current is required. A simple experimental setup using a commercial shaded pole induction motor was designed and fabricated to verify the validity of the FEM analysis. In the test system, the rotor is supported by a linear rail that allows the rotor free rotation and free movement in a vertical direction but not in a horizontal direction. According to the measured step response, stable magnetic levitation suspension was achieved despite a relatively slow settling time due to the large friction force in the horizontal direction.
\end{abstract}

Key words : Magnetically levitated motor, Shaded pole induction motor, Bearingless drive

\section{Introduction}

A magnetic bearing is able to support a rotary shaft by magnetic force without any direct physical contact (Okada 2003, Chiba 2005, Schweitzer 2009) and thus has many advantages that cannot be achieved by conventional mechanical bearings. For instance, there is no frictional wear, low efficiency degradation, low frequency maintenance repetition, and small rotational noise. These advantages make magnetic bearings suitable for long term operation at high speeds or temperatures in clean environments, or even under vacuum. Presently, magnetic bearings are used widely in industry as turbo-molecular pumps, high-speed spindles, energy storage flywheels (Strasik 2010, Han 2012, Werfel 2012), and artificial heart (Hoshi 2006, Kurita 2008).

Despite its benefits, a magnetically levitated motor system tends to be more complex and have a higher risk of system failure than traditional motors due to additional mechanical and electrical components. These additional components lead to an increase in the shaft length and a decrease in the natural frequency of the rotating system. To overcome these problems, the bearingless motor (or self-bearing motor), which is a combination of the motor and the magnetic bearing, has been researched and developed (Chiba 1994, Salazar 2000). The bearingless motor can generate both suspension force and rotational torque, allowing the whole system to be miniaturized and the shaft length shortened.

To achieve active control of all five of the rotor's degrees of freedom (DOF) (radial direction: $x, y$, axial direction $z$; tilt: $\theta_{x}, \theta_{y}$ ), however, a more complex driving circuit is required.

If one allows some DOF to be passively (rather than actively) controlled, the size and complexity of the motor 
system and driving circuit can be reduced. For instance, the radial bearingless motor controls two DOF actively $(x, y)$ while the other three DOF are controlled passively (Schoeb 1997, Okada 2006). In the axial bearingless motor, only one DOF is controlled actively ( $z$ ) (Ueno 2000). Further simplification of the driving circuit can be obtained with the single drive bearingless motor (Asama 2013), which can achieve levitated rotation using only one three-phase inverter.

In contrast to these bearingless motors, the shaded pole induction motor's structure is very simple and very robust, making it one of the most widespread types of single phase induction motor (Morrill 1932, Trickey 1936) especially for driving small, low load fans. Moreover, because the motor is able to generate a rotating magnetic field by using only one alternating-current power, the driving circuit is also very simple.

To leverage the benefits of both the shaded pole induction motor (simplicity and robustness) and the bearingless motor systems (low frictional wear and high speed operation), this paper proposed a magnetically levitated shaded pole induction motor. As in bearingless motors, the rotor is supported by magnetic force, but utilizing the shaded pole motor concept, magnetic levitation and rotation are realizable with only one amplifier.

\section{Shaded pole bearingless motor}

\section{1 Operating principle of the conventional shaded pole motor}

A schematic of the shaded pole motor is shown in Fig. 1. The rotor has a conventional squirrel-cage configuration, but the stator has main windings plus auxiliary, short-circuited windings along a portion of the stator poles. The shaded pole motor generates a rotating magnetic field by applying alternating exciting current to the main windings. Fig. 2 and Fig. 3 show the behavior of the flux lines and average flux density at the upper side airgap, respectively. As shown in Fig. 2 (a) at Time 1, when the positive alternating current applied to the main winding is increasing, an induced current is produced in the auxiliary winding to oppose the flux produced by the main winding. When the alternating current has reached its positive peak value at Time 2 , the induced current at the auxiliary winding is negligibly small and does not affect the distribution of flux produced by the main windings. Thus, the flux is distributed uniformly in the airgap (b). As the alternating current decreases rapidly at Time 3, the flux in the main pole part also decreases, yet the induced current produced in the auxiliary winding maintains the flux at the shaded pole (c). Finally at Time 4, negative current is applied to the main winding, inducing current in the auxiliary winding that again opposes the main flux (d). Because of its placement relative to the main windings, the auxiliary windings aid in producing the rotating magnetic field.

\subsection{Experimental setup}

A schematic of the proposed bearingless motor is shown in Fig. 4. The stator has a main winding and an auxiliary short-circuited winding in a portion of the stator pole, just as in the shaded pole motor discussion above. A permanent magnet (PM) is attached to the surface of the stator pole to support the rotor mass. A displacement sensor is installed under the rotor to detect the rotor displacement.

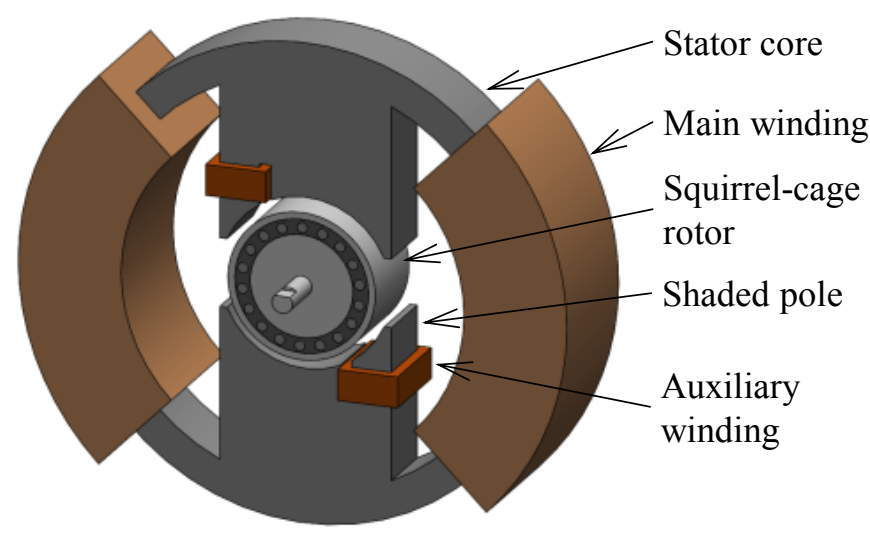

Fig. 1 Structure of a general shaded pole motor 


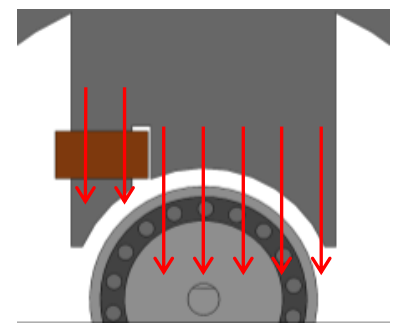

(a) Time 1

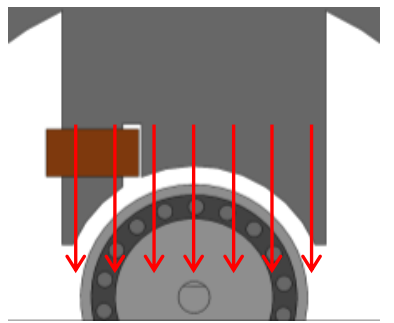

(b) Time 2

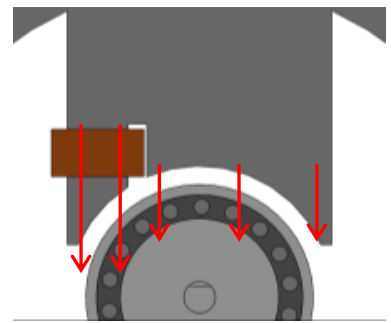

(c) Time 3

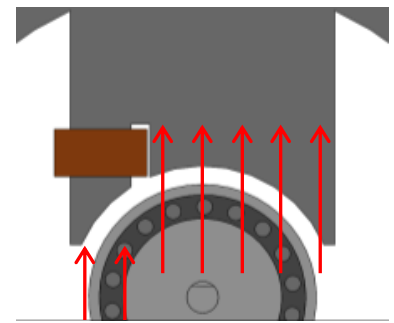

(d) Time 4

Fig. 2 Behavior of the flux line at the airgap

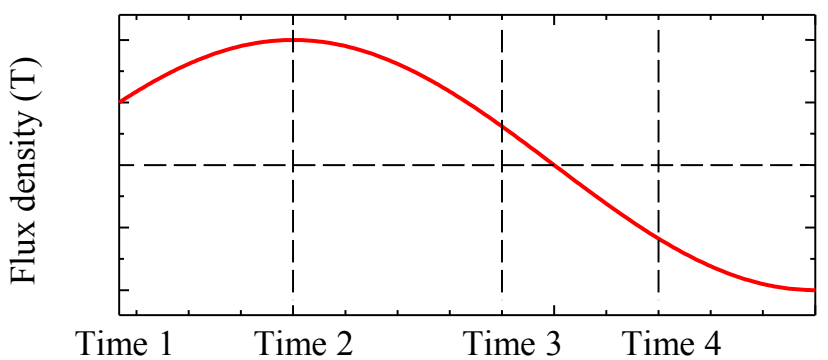

Fig. 3 Average flux density of the airgap

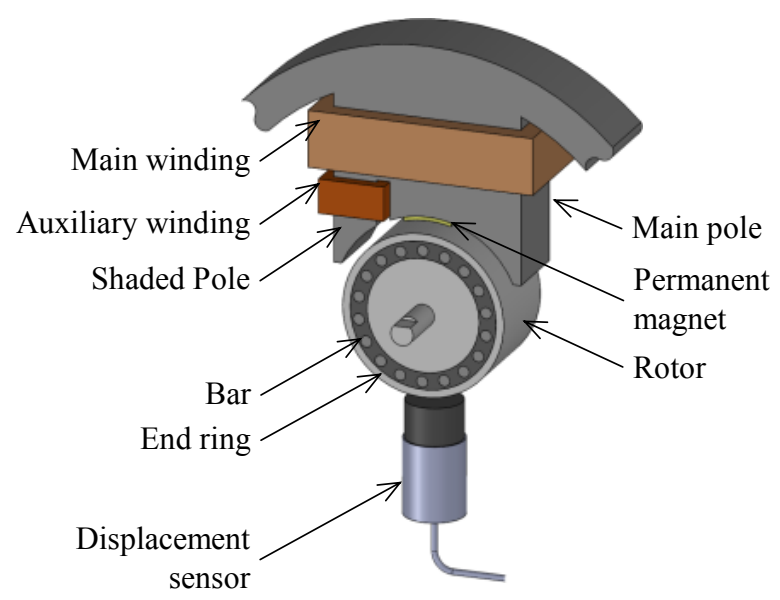

Fig. 4 A schematic of the bearingless motor

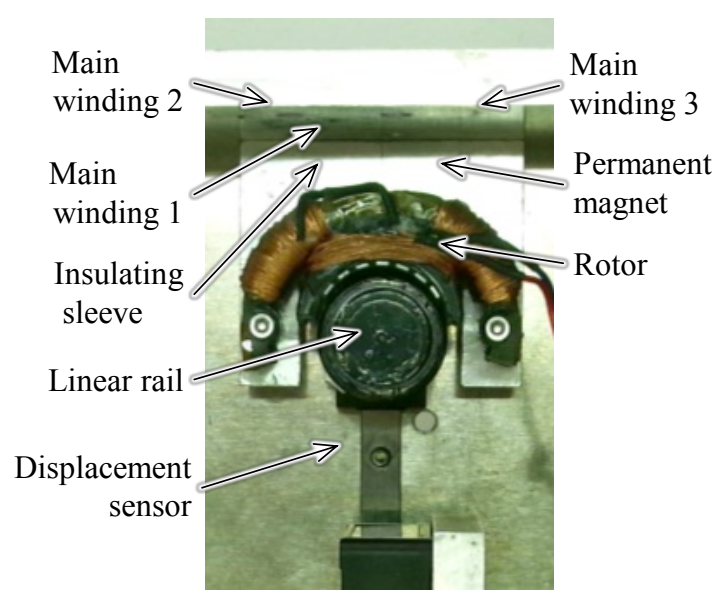

Fig. 5 A photo of the bearingless motor

A photo of the bearingless motor is shown in Fig. 5. Flux density distribution of the shaded pole motor was assumed to be an ideal sinusoidal wave, but in actuality the magnetic flux characteristics are more complex. For simplicity, the experimental device was manufactured using a commercial shaded pole induction motor (NIDEC Servo KAJ55B4) by first cutting the motor stator in half. Three main windings (Main winding 1, 2, 3 in Fig.5) were attached to the stator perimeter and connected in series resulting in a total winding number of 500 turns for the main windings. The shaded winding was also attached to the stator but is covered by an insulating sleeve in Fig. 5.

Unbalanced magnetic field influences on not only vertical direction but also horizontal direction of the rotor. A linear rail supports the rotor so that it can rotate and move in the vertical direction freely, but the linear rail limited horizontal movement. A laser displacement sensor was installed at the lower part of the rotor in order to detect the rotor 


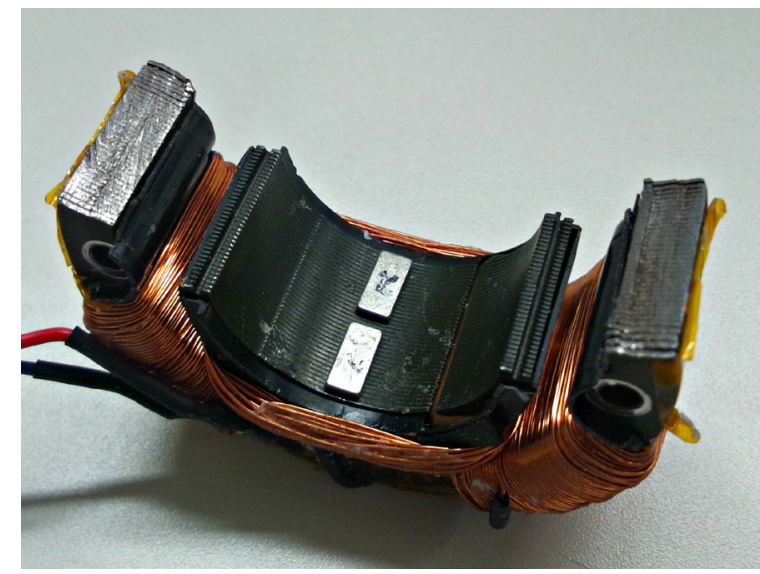

(a) Neodymium magnets

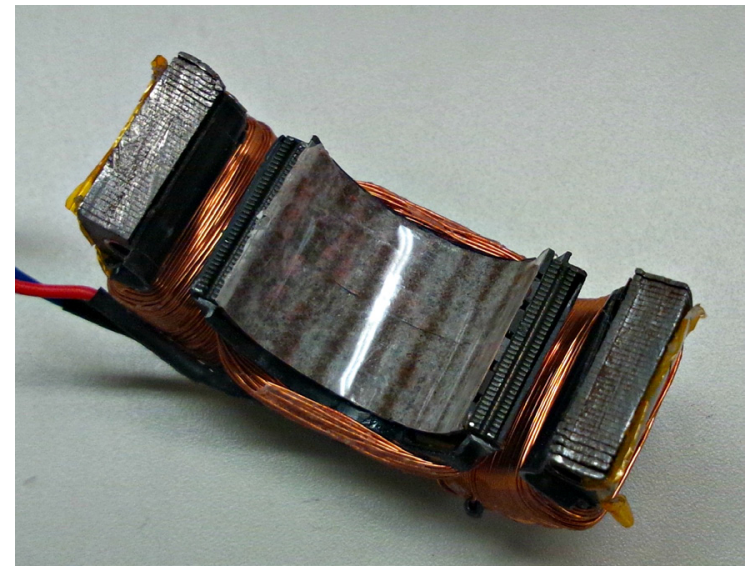

(b) Ferrite magnets

Fig. 6 Photos of the stator

displacement. Horizontal rotor movement was not allowed.

Two different types of PMs were attached to the stator surface in order to produce bias flux. In Fig. 6 (a), two neodymium magnets $(3.5 \mathrm{~mm} \times 8 \mathrm{~mm}$, Thickness: $1 \mathrm{~mm})$ were attached to the center of the stator surface. In Fig. 6 (b), fifty four ferrite magnets $(4 \mathrm{~mm} \times 3.2 \mathrm{~mm}$, Thickness: $0.65 \mathrm{~mm})$ were attached cover the stator surface. The airgap width without PMs is $2.9 \mathrm{~mm}$.

\section{3 Operating principle of the bearingless shaded pole motor}

A block diagram of the bearingless shaded pole motor's control system is shown in Fig. 7. An alternating magnetic field is produced by an alternating current applied to the main winding. The short-circuited auxiliary winding produces a phase lag of the alternating magnetic field. Thus, a rotating magnetic field is produced by adding the main field and the lagged field. Speed is controlled by specifying an amplitude of AC current $\left(\mathbf{A}^{*}\right)$ and a frequency $\left(\mathbf{f}^{*}\right)$. In order to stabilize the rotor position, a levitation control current is applied to the main winding. Based on the rotor displacement, a digital PID controller calculates the position control current. Both the alternating current reference signal to rotate the rotor and the control current reference signal to support the rotor are generated by a digital signal processor. The sum of these signals is input to a linear amplifier that in turn supplies control current to the main winding. The vertical direction of the rotor would levitate with vibrate at the same frequency with the alternating current.

\section{FEM analysis}

\section{1 Confirmation of the operating principle}

In order to confirm the operating principle, an FEM magnetic field analysis was carried out. Fig. 8 shows an analytical model of the manufactured test rig without PMs. An alternating current of amplitude $2 \mathrm{~A}$ and frequency 150 $\mathrm{Hz}$ was applied to the main winding. Analytical result of a $90^{\circ}$ phase difference is shown in Fig. 9 (a). As expected for a conventional shaded pole motor, the induced current at the auxiliary winding is very small. So, it does not affect the main flux distribution of the main windings (refer to Time 1 in Fig 2 and 3). As seen in Fig9 (a), flux line at the stator and the airgap is uniform.

As the flux of the main pole decreases, however, the induced current maintains the flux at the shaded part. Therefore, the flux density of the left side is higher than that of right side, which occurs for a $150^{\circ}$ phase difference (Fig. 9 (b)). When phase difference is $210^{\circ}$, the induced current in the auxiliary winding produces flux to oppose the main flux and the resulting flux density of the left side airgap is lower than that of the right side (Fig. 9 (c)).

These findings confirm that the model is behaving like a shaded pole motor. Ideally, the magnetic flux produced by 


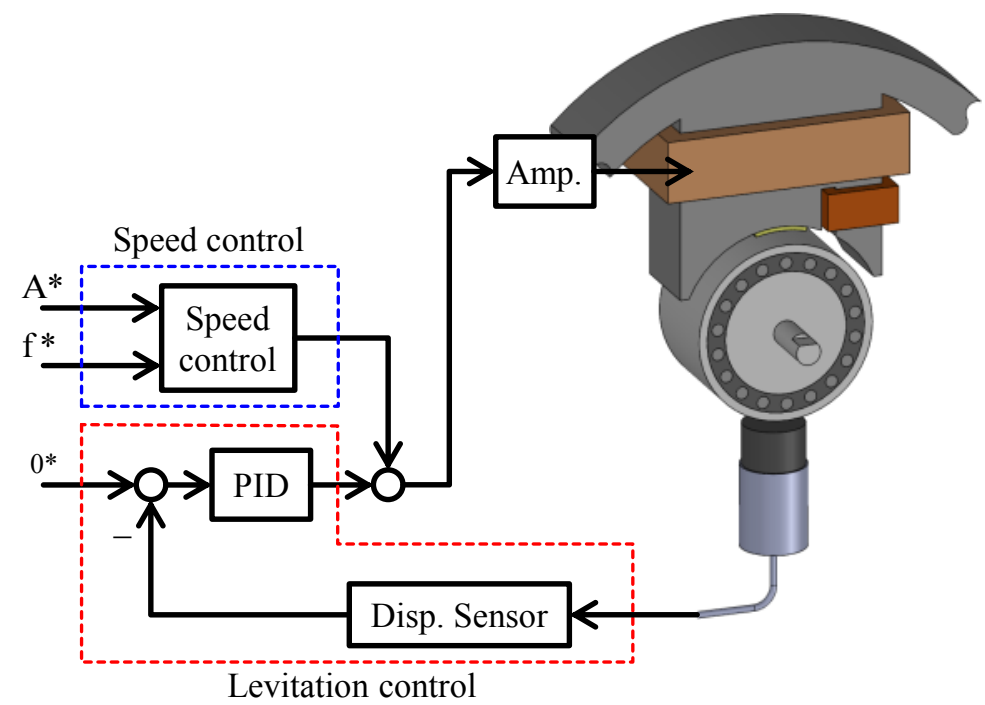

Fig. 7 Block diagram of the control system
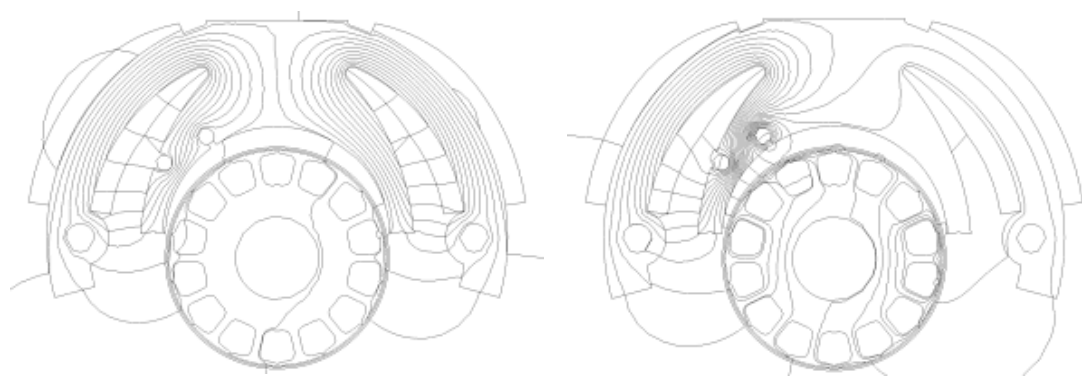

(a) Phase difference: $90^{\circ}$

(b) Phase difference: $150^{\circ}$

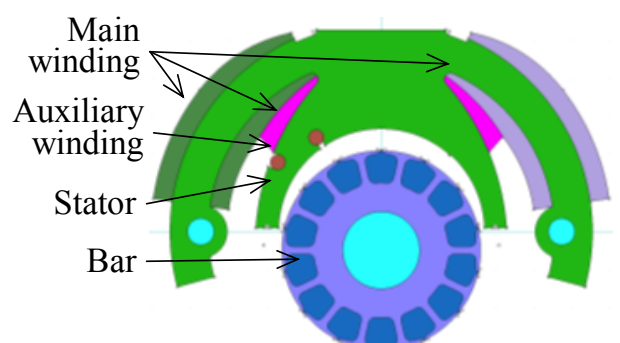

Fig. 8 Analytical model without PM

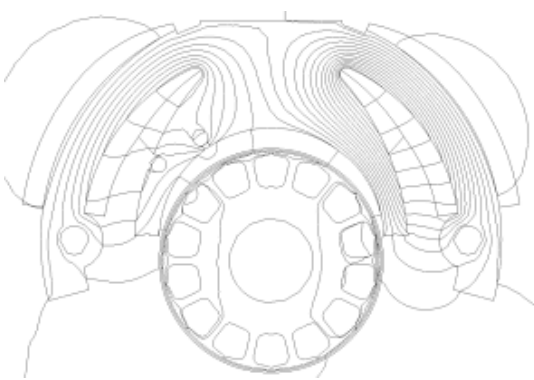

(c) Phase difference: $210^{\circ}$

Fig. 9 Analytical result showing the magnetic flux lines at various phase phases

the main winding should be passed through the stator pole surface to the rotor. However, most of the flux in the simulation has returned from the stator pole to the perimeter part of the stator. This indicates that sufficient magnetic flux is not produced at the airgap. The test rig was manufactured by simply cutting a commercial shaded pole motor and the distance between the stator pole and the perimeter part of the stator was not wide enough. Future setups should include a wider airgap in order to recreate the ideal magnetic flux path at the airgap. In addition, according to the FEM analysis, there is too much flux leakage, thus, it is difficult to consider the effect of the secondary coil in isolation. Therefore, we are currently working on the theoretical development of the operating principle of the proposed motor. Moreover, investigation of the suitable impedance and driving frequency as well as their influence on suspension stability is also important.

\section{2 Suspension force analysis}

To investigate the relationship between the attractive force and the control current, the attractive force was calculated with various direct currents ranging from $-3 \mathrm{~A}$ to $+3 \mathrm{~A}$ with different PMs. Simulation results are shown in Fig. 10 (a) without PM, in Fig. 10 (b) with neodymium PM, and in Fig. 10 (c) with ferrite PMs; Fig. 10 (d) is an overlay of panels (a), (b), and (c). When the direct current is applied, irrespective of its direction, magnetic attractive force acts on the rotor, and the current range for the levitation control is limited to $0 \mathrm{~A}$ to $3 \mathrm{~A}$. As seen in Fig. 10 (b), 
due to the bias flux of the neodymium PM, a bias attractive force of $2.33 \mathrm{~N}$ acts on the rotor with direct current of $0 \mathrm{~A}$. When a negative direct current of $-1.4 \mathrm{~A}$ was applied, the attractive force reached a minimum value of $2.28 \mathrm{~N}$. So in this case, the current range for the levitation control is $-1.4 \mathrm{~A}$ to $3 \mathrm{~A}$. With ferrite PM, a bias attractive force of 0.3963 $\mathrm{N}$ acts on the rotor at $0 \mathrm{~A}$ current. The attractive force minimum value of $0.228 \mathrm{~N}$ occurred when the negative direct current of $-2.4 \mathrm{~A}$ was applied, exciting the levitation control current range from $-2.4 \mathrm{~A}$ to $3 \mathrm{~A}$.

The bias attractive force from the PM supports the rotor weight and the power consumption can be reduced due to the zero bias current. Moreover, bias PMs extend the available control current range. As previously mentioned, there are a lot of leakage flux from the stator to the outer circumference part. The resulting attractive force is weak due to small flux density distribution at the airgap. The stator shape should be redesigned in order to reduce the leakage flux.

\section{3 Rotation torque analysis}

The static torque was calculated with the alternating current at rotating speed of $0 \mathrm{~min}^{-1}$ to study the starting torque characteristics; simulation results are shown in Fig. 11. Fig. 11 (a) shows the analytical results of without PM, with neodymium PM and with ferrite PM. The amplitude of the alternating current is $\pm 1 \mathrm{~A}$ and the frequency is $50 \mathrm{~Hz}$. According to the simulation results, the motor produced an average torque of $0.379 \mathrm{mNm}$ without $\mathrm{PMs}, 0.461 \mathrm{mNm}$ with neodymium PM, and $0.347 \mathrm{mNm}$ with ferrite PM. Without PM motor produced positive torque continuously. Addition of PMs, however, produced positive and negative torque alternately due to the bias flux.

The torque characteristic of the neodymium PM and the ferrite PM motor with an offset-compensated alternating current was investigated by adding a constant offset current of $2 \mathrm{~A}$ to the alternating current of the amplitude of $\pm 1 \mathrm{~A}$ and frequency of $50 \mathrm{~Hz}$ (Fig. 11 (b)). Thus, the maximum current value is $3 \mathrm{~A}$ and the minimum current value is $1 \mathrm{~A}$. According to the simulation result, the torque pulsation became small and negative torque did not occur.

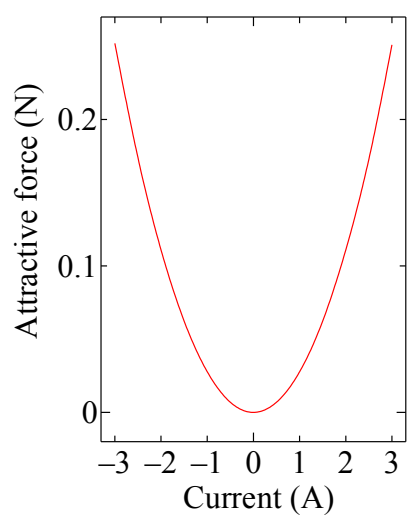

(a) Without PM

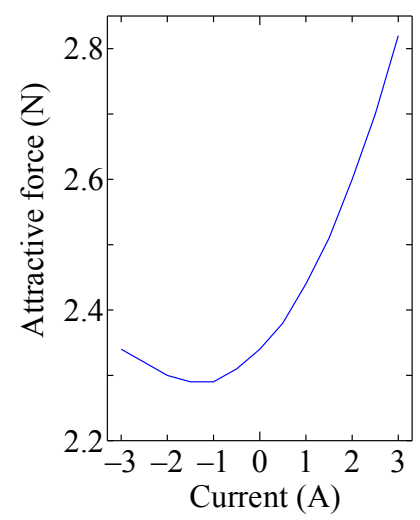

(b) Neodymium PM

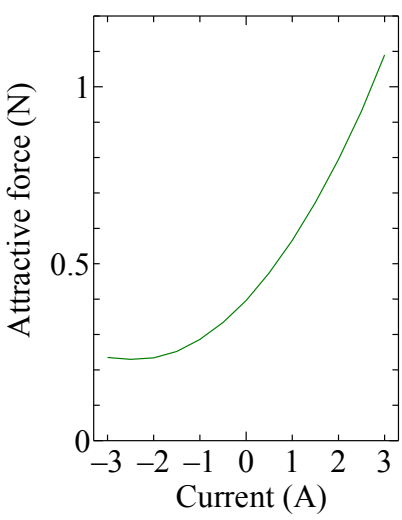

(c) Ferrite PM

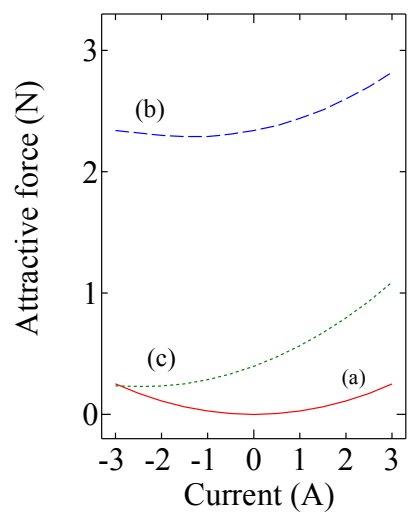

(d) All results

Fig. 10 Simulation results of the attractive force versus control current

\section{Experimental results}

In order to confirm levitation control performance, rotor levitation control with $0 \mathrm{~min}^{-1}$ was achieved and the step response was measured. Once the rotor was levitated stably, a step disturbance which moved the rotor about $0.1 \mathrm{~mm}$ was applied and the rotor displacement and control current were recorded. The experimental result of the neodymium PM motor is shown in Fig. 12. The experimental result showed stable levitation after the disturbance signal was applied, however, the settling time was quite long-about $1.5 \mathrm{sec}$. The magnetic attractive force which acts horizontally to the rotor was not considered in the FEM analysis. In fact, the magnetic attractive force always acts along the rotor axis irrespective of the control current at the portion without the neodymium PM of the stator pole. This leads to a 


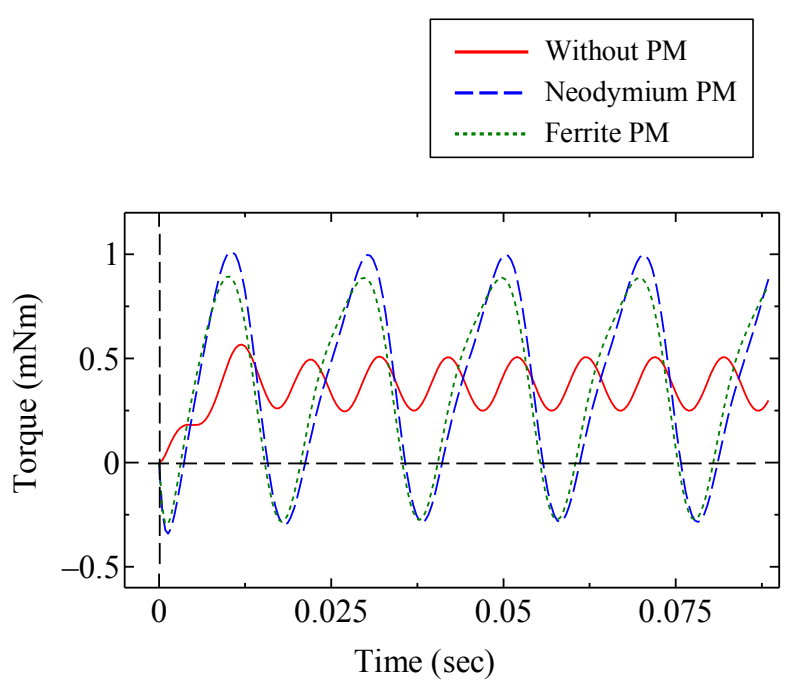

(a) $\mathrm{AC}$ of $\pm 1 \mathrm{~A}, 50 \mathrm{~Hz}$

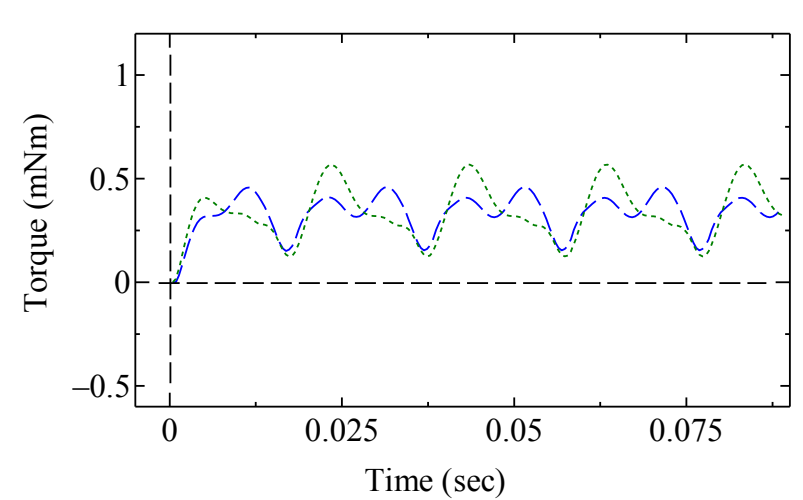

(b) $\mathrm{AC}$ of $+3 /+1 \mathrm{~A}, 50 \mathrm{~Hz}$ with the PM motor

Fig. 11 Simulation results of the rotational torque

friction force on the rail, and the rotor could not move smoothly.

The experimental result of the ferrite PM motor is shown in Fig. 13. The settling time was decreased to $0.5 \mathrm{sec}$, which is three times faster than the neodymium PM motor. The flux produced by one ferrite PM is much weaker than neodymium PM, so in order to produce sufficient amounts of the flux density in the airgap, fifty four ferrite PMs (4 $\mathrm{mm} \times 3.2 \mathrm{~mm}$, Thickness: $0.65 \mathrm{~mm}$ ) were attached to cover the stator surface. In this orientation, the magnetic attractive force acts in the rotor's axial direction in response to the positive or negative direction of the control current. This in turn means a lower friction force on the linear rail and smoother motion

A rotating test was also carried out using a motor without PM. The axial-direction movement of the rotor was fixed, but still the rotor rotates without restriction. An alternating current of $\pm 1 \mathrm{~A}$ was applied to the main winding. The maximum rotating speed of $5,029 \mathrm{~min}^{-1}$ was achieved but levitation was not yet.

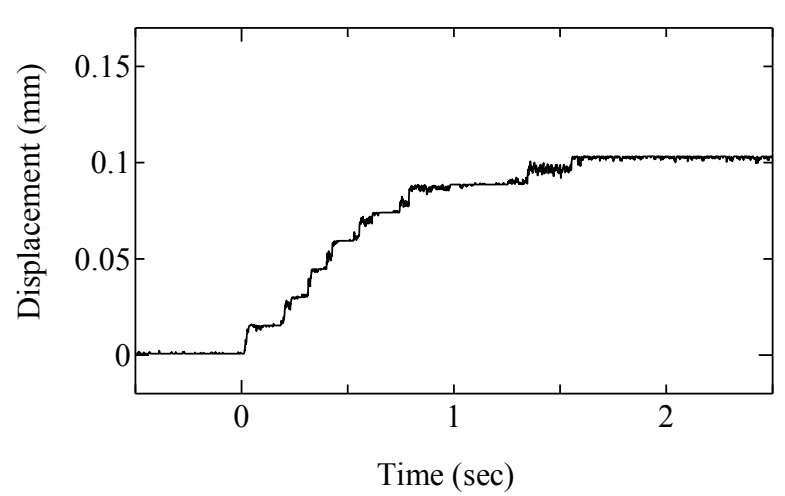

(a) displacement

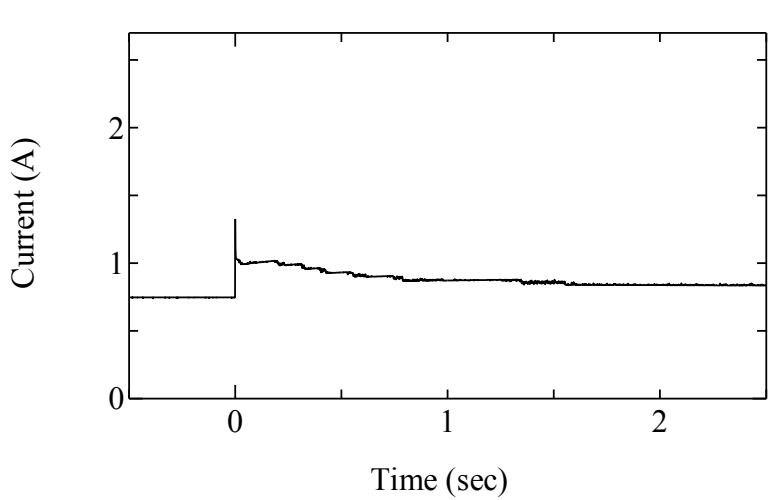

(b) control current

Fig. 12 Step response of the neodymium PM motor 


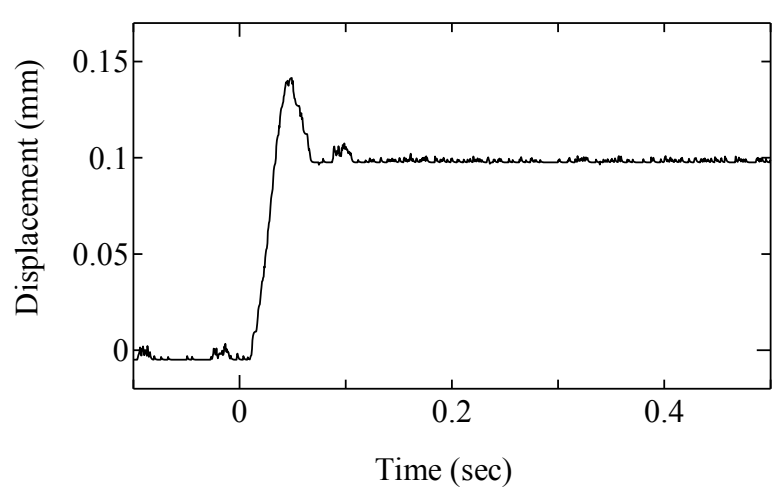

(a) displacement

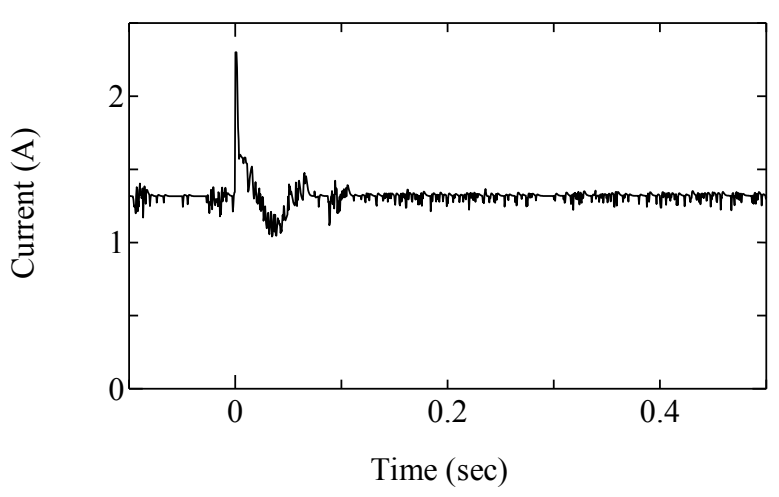

(b) control current

Fig. 13 Step response of the ferrite PM motor

\section{Conclusion}

The magnetically levitated shaded pole induction motor has been proposed as alternative to the bearingless motor in an attempt to reduce the latter's size, complexity, and driving circuit complexity. The operating principle of the proposed shaded pole motor was confirmed by the FEM magnetic field analysis, but the magnetic attractive force was not yet strong enough to achieve levitation due to the leakage flux from stator pole to the perimeter part of the stator.

In order to verify the validity of FEM the analysis, a simple experimental setup was designed and fabricated by using a commercial shaded pole induction motor. Stable levitation control was achieved without rotation by use of the neodymium PM motor and the ferrite PM motor. However, the strong friction force in the rotor's horizontal direction on the linear rail made the settling time very slow. Despite recording maximum rotating speed of $5,029 \mathrm{~min}^{-1}$ in a motor without PM, levitation was not yet possible.

Further work is in progress to achieve levitated rotation of the shaded pole bearingless motor. In order to construct the ideal magnetic flux path, the experimental setup needs to be re-designed with guidance from the FEM magnetic field analysis to reduce the leakage flow from stator pole to the perimeter part of the stator, resulting in higher attractive force. Moreover, it is also necessary to clarify the principle of operation theoretically.

\section{References}

Akira Chiba, Tadashi Fukao, et al., "Magnetic Bearings and Bearingless Drives" Newnes (2005)

Akira Chiba, Tazumi Deido, Tadashi Fukao, Azizur Rahman, "An analysis of bearingless ac motors," IEEE Transactions on Energy Conversion, Vol. 9, No. 1 (1994), pp. 61-68

Andres Salazar, Akira Chiba, Tadashi Fukao, "A Review of Developments in Bearingless Motors", Seventh International Symposium on Magnetic Bearings (2000), pp. 335

F. N. Werfel, U. Floegel-Delor, R. Rothfeld, T. Riedel, B. Goebel, D. Wippich, P. Schirrmeister: "Superconductor bearings, flywheels and transportation", Superconductor Science and Technology, Vol.25 (2012), Paper No. 014007

Gerhard Schweitzer, Eric H. Maslen, et al., "Magnetic Bearings: Theory, Design, and Application to Rotating Machinery", Springer (2009)

Hideo Hoshi, Tadahiko Shinshi, Setsuo Takatani, "Third-generation blood pumps with mechanical noncontact magnetic bearings", Artif Organs, Vol. 30, No. 5 (2006), pp. 324-38

Jindai Saito, "The Air Gap Flux Distribution in the Shaded-Pole Motor", Annals of Toyama University, faculty of engineering, Vol. 5 (1954), pp. 19-21

Jindai Saito, "On the Calculation of the Starting Troque of the Shaded-Pole Motor", Annals of Toyama University, faculty of engineering, Vol. 6 (1955), pp. 7-12

Junichi Asama, Yuki Hamasaki, Takaaki Oiwa, Akira Chiba, "Proposal and Analysis of a Novel Single-Drive 
Bearingless Motor", IEEE Transactions on Industrial Electronics, Vol. 60, No. 1 (2013)

M. Strasik, J. R. Hull, J. A. Mittleider, J. F. Gonder, P. E. Johnson, K. E. McCrary, C. R. McIver: "An overview of Boeing flywheel energy storage systems with high-temperature superconducting bearings," Superconductor Science and Technology, Vol.23 (2010), Paper No. 034021

Nobuyuki Kurita, Daniel Timms, Nicholas Greatrex and Toru Masuzawa, “Axial Magnetic Bearing Development for the BiVACOR BIVAD/TAH", The proceedings of the 11 th International Symposium on Magnetic Bearings (2008), pp. 217-224

P. H. Trickey, “An Analysis of the Shaded Pole Motor", Transactions of the American Institute of Electrical Engineers, Vol. 55, Issue 9 (1936), pp. 1007-1014

Reto Schoeb, Natale Barletta, "Principle and application of a bearingless slice motor," JSME International Journal Serise C, Vol. 40, No. 4 (1997), pp. 593-598

Satoshi Ueno, Yohji Okada, "Characteristics and Control of a Bidirectional Axial Gap Combined Motor-Bearing”, IEEE ASME Transactions on Mechatronics, Vol. 5, No. 3 (2000), pp. 310-318

Wayne J Morrill, "Shaded pole motor", United States Patent, US1884115A (1932)

Y. H. Han, B.J. Park, S.Y. Jung, S. C. Han: "Study of superconductor bearings for a $35 \mathrm{kWh}$ superconductor flywheel energy storage system," Physica C: Superconductivity and its Applications, Vol.483 (2012), pp.156-161

Yohji Okada, Kenzo Nonami, "Research Trends on Magnetic Bearings", JSME International Journal, Series C, Vol. 46, No. 2 (2003), pp. 341-342

Yohji Okada, Takuro Jinbu, Naoto Yamashiro, Kouji Sagawa, "Lorentz Type Self-Bearing Motor using Halbach Magnets”, Proceegings. of Tenth International Symposium on Magnetic Bearings (2006), pp. 1-6 